\title{
FUNDAMENTOS ANTROPOLÓGICOS Y PEDAGÓGICOS PARA UN PROYECTO DE EDUCACIÓN PARA LA PAZ
}

Ramón Moncunill Bernet

\section{RESUMEN}

La educación para la paz puede parecer una utopía, un sueño quimérico e irrealizable, o una necesidad imperiosa ante los profundos cambios socioculturales planteados en este comienzo de siglo. En un mundo cada vez más globalizado e intercultural, donde las relaciones - pero también los contrastes y conflictos- entre personas, culturas y naciones cobran un protagonismo más acelerado y real que en épocas anteriores, se hace cada vez más urgente, en el ámbito de la formación de nuestros jóvenes, plantearse la necesidad de educar para la paz, es decir, educar en aquellos valores - como el espíritu de solidaridad y el compromiso por servir al bien común - que ayuden, en definitiva, a fomentar lo que nos une, por encima de las diferencias que nos separan.

\section{INTRODUCCIÓN. ¿CRISIS DE VALORES EN LA SOCIEDAD EUROPEA?}

Somos plenamente conscientes que nos toca vivir un momento histórico apasionante y al mismo tiempo delicado. Asistimos en los últimos años a la caída de la ideología marxista, que configuró buena parte de la historia de Europa y de medio mundo en los últimos cien años; el nuevo brote de nacionalismos que, en muchos ocasiones, no se han canalizado 
adecuadamente y que han desembocado en guerras fratricidas (como en el caso de la antigua Yugoeslavia o algunas de las antiguas repúblicas soviéticas); conflictos armados en muchos lugares como Angola, Sudán y otras naciones africanas, por citar sólo unos ejemplos.

Tensiones y rivalidades que hacen de la paz un equilibrio totalmente inestable como en Oriente Medio con sus dramas de impredecible futuro. Situaciones de injusticia manifiesta alimentadas muchas veces por la indiferencia de Occidente por no se sabe qué razones, como en el Congo, Somalia, Ruanda, Burundi y otras naciones africanas, el Kurdistán, etcétera.

La construcción de la Europa de las Naciones es proyecto ambicioso pero que debe vencer múltiples dificultades, como los recelos mutuos y la prepotencia y egoísmo de algunos, sin olvidar los temores de muchas naciones latinoamericanas, cuya deuda externa atenaza sus esperanzas de progreso.

También la desconfianza y temores que suscita la llamada "globalización" por parte de ciertos movimientos sociales - no exentos de ser manipulados- que denuncian el riesgo de caer en un neoliberalismo radical e inhumano únicamente benéfico para las naciones poderosas, acrecentando así el abismo entre países pobres y ricos.

Todo este panorama - que ilustra sólo la cuestión de fondo y no agota todos los elementos en conflicto- nos sitúa por una parte frente a la responsabilidad propia, de cada uno, por construir un mundo mejor y, por otra, nos lleva a discernir que el modelo de desarrollo puesto en práctica hasta hoy en Occidente no resulta satisfactorio para resolver la relación Este-Oeste y Norte-Sur; quizá no hemos acertado en el estilo de ayuda de Occidente al Tercer Mundo.

Aunque se hable de un Nuevo Orden Mundial, éste todavía se halla en fase de proyecto y, si no está bien fundamentado, difícilmente pasará de ser un piadoso sentimentalismo o un repertorio de buenas intenciones. 
No puede fundamentarse un Nuevo Orden Mundial sin unos valores que le den consistencia y sentido. Y surge, así, la primera pregunta: ¿Cuáles valores están, hoy por hoy, en alza? Si analizamos la sociedad actual $-\mathrm{y}$ fundamentalmente me refiero a la europea y occidental-, nos encontramos que los valores que configuran el tejido social son el bienestar económico, el prestigio personal, el dominio sobre los demás y la consecución del éxito — profesional, social o económicoa cualquier precio.

¿Es posible crear un mundo mejor con estos valores - contravalores, diría- que enmarcan al otro hombre, no como al prójimo a quien hay que ayudar, sino como al enemigo a quien hay que vencer y pisotear? Ciñéndonos un poco más al mundo occidental y a nuestra reciente historia, sería interesante constatar cómo en los antiguos países comunistas el sistema político imperante propició la pasividad de espíritu, lo cual engendró una especie de autismo colectivo que hizo a las personas replegarse en sus vidas privadas. El poder se dio cuenta de eso y aprovechó la situación en su beneficio, proporcionando a sus ciudadanos un bienestar material — diría una seguridad-que adormeciese sus conciencias. Toda una filosofía de fondo que llevó a la falta de iniciativa personal, de preocupación por los demás, de generosidad. El marxismo prometió un paraíso en la tierra pero ocultó que el precio a pagar era la renuncia de la persona a su propia razón, a su conciencia y a su responsabilidad. El mundo de Kafka y Orwell se hizo realidad en los países del Este. La cuestión de fondo no es política, es filosófica, es ética. Esta misma reflexión se expresa, de forma muy parecida, en la famosa CARTA'77 cuando Valclav Havel afirmaba que la crisis social, que entonces se vivía en Checoeslovaquia, era esencialmente una crisis ética ${ }^{1}$.

${ }^{1}$ Cfr. ACEPRENSA, Servicio 33/90: Una revolución de la existencia. 
Ahora bien, ¿pensamos que el Occidente de la economía de mercado capitalista, del progreso y de las libertades - expresiones y conceptos ambiguos que muchas veces no se sabe bien qué quieren significar - estuvo y está al margen del mismo problema? Este peligro, por otra vía, también se da en Occidente, un Occidente regido por los principios de la sociedad de consumo donde algunos gobiernos parecen tratar de reducir al ciudadano a la categoría de un animal satisfecho en sus necesidades básicas, que vota y paga impuestos.

Por caminos distintos, pues, las consecuencias de estos dos postulados materialistas son la pérdida de los valores y convicciones morales, la creencia en ideales e ideas propias, la muerte de la cultura y la consagración de la banalidad —el pensamiento débil—y la mediocridad.

El abandono del marxismo no signfica encontrar, automáticamente, un nuevo fundamento vital. La pérdida de una ideología que antes sustentaba la vida puede desembocar finalmente — como apunta Ratzinger - en el nihilismo; el relativismo moral que impera en la actualidad desarrolla una creciente inclinación al nihilismo². Ésta es la cuestión de fondo: ¿con qué contenidos llenar el vacío espiritual creado como consecuencia del fracaso del experimento marxista? ¿Sobre qué fundamentos éticos construir un futuro común, en el cual el Este y el Oeste se vinculen en una nueva unidad, pero también el Norte y el Sur encuentren un camino común?

\section{VALORES EDUCATIVOS PARA UN MUNDO MEJOR}

La fuerza de la llamada "aldea global" no puede provenir, principalmente, de su prosperidad económica o de unos acuerdos políticos. En este sentido es evidente que las escuelas pueden contribuir de manera decisiva a generar una sociedad mejor en los aspectos más fundamentales y es triste constatar que, en todo este proceso, la voz de los agentes educativos ha

${ }^{2}$ Cfr. RATZINGER, J., Una mirada a Europa, p. 111-126. 
sido poco solicitada o simplemente ignorada. Parece como si fuera suficiente con una armonización de intereses económicos y una voluntad política de los dirigentes de los Estados. La prosperidad económica europea, a partir de los años 50, ha producido un viraje que todavía no hemos superado. Una parte importante de nuestros conciudadanos se ha dedicado obsesivamente a mejorar sus condiciones materiales sin preocuparse de las otras dimensiones de su vida humana. Se ha identificado calidad de vida con nivel de consumo, empobreciendo así el mismo concepto de persona. Las cuestiones decisivas para la construcción de esa llamada "aldea global"son, por una parte, la identificación de valores comunes y, por otra, el reconocimiento de que los protagonistas de la aventura europea son todos y cada uno de los ciudadanos que deciden vivir por convencimiento y no por imposición de sus dirigentes políticos, estos valores comunes. Es en estos valores comunes - susceptibles de ser transmitidos, de ser educados - donde debemos enfatizar nuestra acción formativa: el desarrollo de una conciencia ética capaz de establecer marcos de referencia claros, es decir, la concepción del humanismo cristiano como fundamento de orden de la convivencia al servicio de la persona.

La importancia de los saberes humanísticos — que es conocimiento del hombre y de la historia, el arte de comunicarse y dialogar, disciplina de la razón y el pensamiento- se constituye como básica si queremos salvar al hombre de reduccionismos mecanicistas y alienadores. Se constata dramáticamente cómo, en muchos países con altos niveles de cultura técnica y científica, se produce un grave desequilibrio entre el buen nivel de conocimiento y una preocupante carencia de formación ética. No hay educación sin cultura moral, especialmente en un momento histórico en el cual disponemos de poderosos instrumentos para incidir sobre las personas, las sociedades y los Estados.

La dimensión interior — moral— de una sociedad se muestra en los valores que ésta considera como dignos de protección. 
La escuela se constituye como un ámbito privilegiado para acoger y sensibilizar a los alumnos respecto a la dignidad de todas las personas, independientemente de su etnia, religión, riqueza, cultura o ideas.

El futuro no podemos pensarlo imaginando la creación de una sola cultura, resultado de la mezcla de todas las existentes, pero tampoco como una coexistencia de culturas exclusivas en sus territorios respectivos. El futuro que tendremos es de multiculturalidad en formas e intensidades diversas y hemos de saber contemplarlo como una oportunidad enormemente positiva para cada cultura. Sin embargo, es preciso prepararse para este futuro.

Cada ciudadano, habitante en su cultura propia, debería poder circular sin problemas y con alegría por otra o diversas lenguas o culturas de diferente país. El mismo criterio puede utilizarse para acoger con respeto e interés cultural a los inmigrantes procedentes de otros continentes, que llegan marcados por un patrimonio cultural, lingüístico, religioso y estético muy diferente al nuestro. El diálogo será difícil, pero también apasionante.

Es legítimo discutir los criterios que han de regular las migraciones entre países, pero nuestro futuro no es pensable sin contar con una importante inmigración. Las culturas que parecen exóticas son tan respetables como las nuestras y pueden contribuir a un debate serio sobre los problemas comunes de la humanidad. Los europeos hemos de vencer nuestra ignorancia respecto a las culturas y lenguas de otros continentes. La escuela, pues, es el lugar idóneo para formar al ciudadano en estos nuevos valores y circunstancias que acabamos de exponer.

\section{QUÉ SE ENTIENDE POR EDUCACIÓN PARA LA PAZ}

Todo lo expuesto hasta aquí no es ajeno al tema central que nos atañe: la educación para la paz.

Entre otras cosas - y ésta es una cuestión vital - porque la educación para la paz no constituye ni puede constituir una 
lección o un tema a desarrollar en una asignatura determinada - por ejemplo en Ética o Historia-, o un apartado al margen de los objetivos principales de la vida escolar, o surgido como el capricho o la ilusión de un profesor soñador. La educación para la paz debería hacerse presente en el proyecto del Centro Educativo como uno de sus objetivos básicos.

Cuando se estudia el tema de la paz es ya tradicional distinguir entre paz positiva, paz negativa y paz personal.

El concepto de paz negativa lo definíríamos como ausencia de conflicto bélico o como estado de no-guerra. Si profundizáramos un poco más, diríamos que es la paz resultante de la sumisión —entendida como sumisión de las voluntades a un poder que las domina-, o la que resulta del equilibrio - equilibrio de fuerzas; antagonismos que no se convierten en guerra porque ninguno se atreve a atacar a su rival—, o la paz como resultado de la neutralidad donde se ignoran unos a otros, que no es ni amistad ni guerra sino más bien soledad; estas tres vertientes de paz — sumisión, equilibrio y neutralidad- definirían la paz en sentido negativo. Ya se ve que es algo, pero tremendamente insuficiente; la paz que resulta de la solidaridad y de la amistad es de una calidad muy superior. Sin embargo, desde una paz entendida fundamentalmente como ausencia de guerra, la educación para la paz se concibe como educación para crear opinión en contra de la guerra y el odio entre los pueblos. De algún modo es también el enfoque dominante en lo que hoy llamamos educación para el desarme, cuando ésta se centra en favorecer actitudes de rechazo hacia la carrera de armamentos y al sistema de guerra en general. Pero si en la educación para el desarme se incluyen, además, implicaciones socioeconómicas y ecológicas de la carrera de armamentos, su relación por tanto con el subdesarrollo y los derechos humanos, se desbordan ya claramente los marcos de referencia de una paz entendida en sentido negativo, acercándonos a una concepción positiva de la paz. 
El concepto de paz personal se define como tranquilidad personal, ausencia de conflictos. Desde una paz entendida fundamentalmente como armonía interior, la educación por la paz se concebirá como cultivo de las actitudes de serenidad, confianza en sí mismo, dominio de sí, disposición de servicio, relaciones armoniosas con los demás y la realidad que nos rodea, etcétera. Aunque se trata de una aportación valiosa, corre el peligro de reducirse meramente al cultivo de buenos sentimientos.

Finalmente llegamos al concepto de paz positiva que no es sólo ausencia de conflicto bélico sino ausencia de violencia entendida en su doble connotación: personal y estructural. Como expresa Ledarach: "No puede haber paz positiva si hay relaciones caracterizadas por el dominio, la desigualdad y la reciprocidad, aunque no haya conflicto abierto". También el profesor Dondeyne define la paz positiva como el comienzo de la comprensión mutua, del respeto y aprecio del otro en cuanto diferente de nosotros. Por eso D. Pire — premio Nobel de la Paz- insiste en que la paz positiva es coexistencia de espíritus y corazones, y que depende de hecho de cada uno de nosotros. Desde esta perspectiva, la educación por la paz debe fomentar la concientización hacia las causas de la guerra y de la paz, fomentar actitudes de rechazo de la violencia directa en sus variadas formas (terrorismo, torturas, agresiones diversas), pero fomentar igualmente la capacidad de analizar las estructuras socioeconómicas con vistas a superar la violencia estructural.

La educación por la paz será también, en este sentido, educación para los derechos humanos y para el desarrollo. La educación para la paz no puede ser una actividad meramente teórica; debe motivar tomas de posición que generen comportamientos activos en favor de la paz.

Éste es un punto crucial: la educación para la paz es una educación para la acción; para mejorar nuestra solidaridad, desarrollar actitudes y comportamientos de respeto a los 
demás. La educación para la paz no es inhibición de la agresividad sino afirmación positiva del espíritu de servicio, es cultivo de la diversidad, fomento del autoconocimiento y desarrollo de la confianza en uno mismo y en los demás; desarrolla las capacidades de toma de decisiones y de resolución no violenta de los conflictos; es comprensión multicultural e intercultural y se fundamenta en los derechos que todo ser humano tiene por el hecho de serlo.

La paz nace de lo profundo de la propia persona y debe ser entendida como experiencia a la que todos tenemos derecho y de la que nadie puede ser privado. Desde esta perspectiva, la paz se nos presenta como compromiso por el cual hay que apostar y trabajar.

La paz, que nace en el corazón del hombre, transforma la realidad haciéndola más habitable y constituyendo la justicia como medio oportuno para su aparición. Por ello, al hablar de compromiso, afirmamos que debemos esforzarnos para crear el ambiente oportuno, un ambiente de justicia necesario para que se dé la paz. Como señalábamos en el primer apartado de este ensayo, en una sociedad individualista y trepadora - donde los valores de colaboración y trabajo en grupo han sido sustituidos por la competitividad más feroz-, si nosotros, los educadores y padres de familia, no apostamos por este estilo, no esperemos ver a nuestros hijos convertidos en "artesanos de la paz". Hemos de transmitir este estilo con nuestra vida coherente y no sólo mediante el consejo o el discurso. Es la fuerza del ejemplo y del testimonio. El ejemplo de un padre, de una madre que, sin descuidar su hogar, se ocupen de una obra, un movimiento, de una tarea social, religiosa o cívica, contribuye a despertar en el alma de los hijos el sentido de la generosidad. No lo olvidemos: los valores se transmiten por contagio, viéndolos, comprobándolos en el estilo del educador. 


\section{FUNDAMENTOS ANTROPOLÓGICOS DE UNA EDUCACIÓN PARA LA PAZ}

Iniciamos un tema que para mí constituye el núcleo y centro vital de toda la exposición. Hemos mencionado ya, al hacer un diagnóstico de la sociedad occidental, la crisis de valores y cómo, indudablemente, ésta debe tener un reflejo y una incidencia grave en la tarea de educar y en la función del educador. En efecto, en un ambiente social que menosprecia los valores por tratarlos de dogmatismo y falta de espíritu tolerante, que pone en tela de juicio los valores de los padres y los preceptos religiosos, en estas circunstancias el profesorado, la escuela, se encuentra como incapacitada, inerme, para proponer nuevos valores morales y ha limitado sus esfuerzos a reducir la educación a la mera transmisión de conocimientos y capacidades técnicas. Así no se arregla el problema.

Si se concibe la educación sólo, meramente, como transmisión y almacenamiento de datos, cifras y fórmulas no mejoramos al hombre, no transformaremos a la sociedad. La cuestión de fondo es una cuestión ético-antropológica y la educación para la paz es, por tanto, de entrada, una cuestión ética.

Los males sociales - guerras, odios, injusticias, corrupción, fraudes económicos, escándalos políticos, información sectaria en los medios de comunicación, etcétera- son consecuencia de la propia enfermedad moral de la persona.

La cuestión es ésta: si queremos que el hombre obre bien, debe pensar bien. Es decir, hay que educar — formar- la conciencia para que su obrar se adecue a su pensar. Es un giro radical. La educación, la tarea educativa, se presenta como un gran esfuerzo ético, como un gran reto por fundamentar los valores que queremos transmitir. Ya lo afirmaba Platón: “La buena educación hace hombres buenos y que los hombres buenos actúen noblemente».

No cabe duda de que la Declaración Universal de los Derechos del Hombre ha supuesto un gran avance al poner de 
relieve un conjunto de nociones - impregnadas muchas de ellas de tradición cristiana, como por ejemplo la misma noción de dignidad humana-impuesto como sistema universal de valores.

Sin embargo es triste observar que, aceptándolos prácticamente todas la naciones del mundo, también se constata que tal vez nunca como hoy han sido y son fácilmente conculcados. ¿Por qué? Si dejamos aparte el misterio de la libertad del corazón humano — sus grandezas y sus miserias, y su natural condición en este mundo terreno-, habría que profundizar en causas de tipo filosófico.

La Declaración Universal de 1948, aun siendo una valiosa aportación, no presenta los fundamentos antropológicos y éticos de los derechos que proclama. Es cierto que existen posturas, como la de Norberto Bobbio, negadora de la posibilidad de un fundamento absoluto de los derechos humanos, pero no es sino consecuencia de la carencia filosófica de sus planteamientos, es decir, es la ausencia de una metafísica que sustente la realidad personal, lo que le impide dar ese paso. Hay que proporcionar bases morales al edificio jurídico de los derechos del hombre.

La dignidad de la persona no puede tener como fuente y fundamento una mera declaración de derechos humanos. Estas declaraciones - pese a la altura de miras que pudieron inspirarlas - han quedado prácticamente reducidas a hermosas exposiciones platónicas, quebrantadas a menudo por los mismos Estados que las suscribieron. La razón última de este fracaso se halla en la diversidad de concepciones acerca de la naturaleza de la persona en que se inspiraron.

Es necesario señalar que a pesar de la diversidad, toda persona posee una naturaleza bumana esencialmente idéntica; ahora y hace treinta siglos, aquí en Occidente y en el extremo Oriente; todo hombre se define y manifiesta por la conciencia, la libertad, la participación, el autodominio y la trascendencia. Ésa es la base antropológica común a toda persona. La dignidad estriba en tener conciencia clara del valor de la condición humana y vivir de acuerdo con las exigencias que esta condición impone. 
Una antropología trascendente ha de afirmar siempre que la piedra angular de la dignidad humana la constituye su condición de criatura, hecha por Dios a imagen suya. El hombre es una criatura; pero criatura esencialmente distinta de las demás y la única en la que se da una misteriosa pero inequívoca semejanza con el Creador. Éste es el decisivo hecho diferencial, el título de grandeza que justifica la valía incomparable del hombre. Una criatura que lleva la impronta de la semejanza con Dios es un ser respetable, por razón de su misma naturaleza.

Los derechos humanos entendidos como exigencias de la dignidad de la naturaleza humana, que nacen por tanto de cada hombre, se fundamentan en la dimensión transcendente de la persona, donde está la fuente de su dignidad y de sus derechos inviolables, y en ninguna otra parte.

Cuando se deja a un lado el fundamento absoluto de los derechos humanos se corre más riesgo de atropellar los derechos concretos (por ejemplo, el derecho a la vida del niño en el seno de su madre). El hombre tiene necesidad de la trascendencia. La pura inmanencia le queda demasiado estrecha. Ha sido creado para algo más. La negación de la transcendencia condujo inicialmente a una glorificación apasionada del vivir, a la afirmación de la vida a cualquier precio.

Sin trascendencia no hay fundamentos del Derecho. Cuando Dios y las formas fundamentales de la existencia humana, creada por Él, son eliminadas de la mentalidad común y reducidas a actuar en lo privado, en la esfera necesariamente subjetiva, la propia noción del Derecho se desvanece y, con ella, el fundamento de la paz. Lo señala también, con otras palabras, Kolakowsky: "Cuando no hay Dios, no hay moral, no hay ni siquiera el hombre, ${ }^{3}$.

Es ahora, una vez fundamentados los derechos de toda persona, cuando tiene sentido hablar de paz, de justicia, de solidaridad, porque no nos basamos en subjetivismos, en

${ }^{3}$ KOLAKOWSKY, L. , El Hombre sin Alternativa, Alianza , Madrid, 1970. 
consensos morales relativos y precarios que no establecen nada como bueno o como malo porque son incapaces de aceptar el mismo concepto de amor a la verdad y amor al bien como términos absolutos. Valclav Havel lo entendió cuando afirmaba: "La motivación ética nos empuja a hacer el bien por principio, por amor al bien. El bien como tal tiene siempre un sentido ${ }^{4}$. La verdad sirve a la causa de la paz; la no-verdad - la mentira, la información parcial y deformada, la manipulación de los medios de comunicación, el no reconocer los derechos legítimos de los que no piensan como nosotros - sirve a la causa de la violencia. No hay paz sin justicia y sin libertad. Primero debemos buscar la verdad objetiva y universal sobre el hombre.

La verdad fortalece la paz desde dentro, y un clima de sinceridad más grande permite movilizar las energías humanas para la sola causa que es digna de las mismas: el pleno respeto de la verdad sobre la naturaleza y el destino del hombre, fuente de la verdadera paz en la justicia y la amistad.

Hablar de paz, hoy, es hablar de justicia y solidaridad. El compromiso en favor de la justicia debe estar íntimamente unido con el compromiso en favor de la paz en el mundo contemporáneo.

En un mundo distinto, dominado por la solicitud, por el bien común de toda la humanidad —o sea por la preocupación por el desarrollo espiritual y humano de todos-, en lugar de la búsqueda del provecho particular, la paz sería posible como fruto de una justicia más perfecta entre los hombres.

La paz del mundo implica la transformación de la mutua desconfianza en colaboración. Éste es, precisamente, el acto propio de la solidaridad entre los individuos y las naciones.

\section{FUNDAMENTOS PEDAGÓGICOS: ¿CÓMO EDUCAR PARA LA PAZ?}

En la carta de constitución de la UNESCO, figura la siguiente sentencia: "Las guerras nacen en el espíritu de los 
hombres; es en el espíritu de los hombres donde deben ser levantadas la defensas de la paz"

Llegamos, por fin, a la fase operativa en la que, después de haber fundamentado los postulados éticos y antropológicos de una educación para la paz, debemos descender al cómo, a establecer los mecanismos que hagan factibles y viables esos grandes objetivos.

Sin embargo, no podemos caer en reduccionismos fáciles ni fórmulas mágicas. Toda tarea educativa supone un proceso de mejora en el desarrollo de capacidades, un cultivo de virtudes. Al educador no se le piden milagros sino la actitud coherente de enseñar lo que él mismo vive, la entrega generosa y una intencionalidad clara hacia unos objetivos que se marcan como contribución a ese proceso de mejora.

Educar para la paz será educar en los valores, sabiendo que un valor no es lo que está de moda sino todo aquello que puede ser un medio para la dignificación personal, siempre que la persona lo asuma responsablemente. Los valores sólo pueden darse a conocer y hacerlos desear a base de vivirlos plenamente, de expresarlos con la palabra de nuestra vida, de apoyarlos con el propio testimonio.

Aunque es una idea reiterada, hemos de insistir en ella: el ejemplo como fuerza de persuasión.

No pretendamos que los hijos mejoren y construyan un mundo de paz si padres y profesores no somos capaces de enseñarles y, sobre todo, mostrarles con nuestro ejemplo diario que ese ideal es aquel que constituye la ilusión de nuestra vida.

Actitudes educativas a fomentar serán, entre otras, las siguientes:

1. Enseñar a perdonar. Sólo quien es capaz de perdonar puede edificar la paz y conservarla.

2. Educar personas abiertas al espíritu, como oposición a una visión materialista y consumista de la vida. Es, en el fondo,

${ }^{5}$ SCHELEGEL, F., Kritische Fragmente, Aathenäum, 1798. 
la cuestión de dar grandes ideales a la juventud y motivos - lo que dé sentido a mi vida - que justifiquen la entrega a favor de una causa justa.

3. Darles a entender el sentido del dolor, de la enfermedad, de la muerte. Si no podemos mostrar una imagen de la vida en la cual el dolor, la preocupación, la muerte estén llenas de significado y se inscriban en una totalidad mayor, entonces no podremos rehabilitar la vida del hombre. Y no se nos escapa que, tal como dice V. Havel, la vida sólo puede tener sentido completo desde perspectivas transcendentales.

4. Buscar y educar el sentido de lo gratuito; lo que se hace sin esperar la recompensa, por nobleza de espíritu. Ese darse gratuitamente es incompatible con un stablishment fundamentado en el tener, y no en el ser, una civilización consumista y materialista - la de nuestros días-, de técnicos, de especialistas donde todo se juzga en función de la eficacia y donde la única moral que impera es la del "éxito" social y económico a toda costa y a cualquier precio.

5. Espíritu de lucha, sentido positivo. Evitar el desánimo ante las decepciones o la indiferencia.

6. Desarrollo de la virtud de la alegría. Puede parecer extraño, pero estoy convencido que una persona alegre habrá dado un salto cualitativo hacia el amor a la paz. Vivenciar la auténtica alegría que hace que los otros placeres —el placer del éxito, de la victoria, de la recompensa y del propio provecho- resulten insípidos.

Complementariamente a estas actitudes educativas -marco en el que se circunscribe nuestro quehacer educativo-, señalaría una líneas de fuerza, unos objetivos intencionales claros para dar respuesta eficaz a la pregunta que nos atañe: ¿Cómo educar para la paz?

Se trata, a mi juicio, de potenciar unas virtudes humanas que, sin descuidar otras, constituyen pilares sólidos de la madurez humana. 
En primer lugar, la educación de la generosidad. Educar en la generosidad no es opcional, es fundamental para que la persona llegue a su plenitud, para que se autoposea y para que sirva mejor a los demás. La sociedad de consumo fomenta el egoísmo y la comodidad. Hablar de generosidad es hablar de una manifestación del amor y precisa darle motivos, un por qué, que fundamente ese utilizar la voluntad para acercarse al bien.

Difícilmente existirá una generosidad en desarrollo permanente si, en el fondo, la persona no vive la generosidad por una convicción profunda de que los demás tienen derecho a recibir su servicio, de que la vida es para servir. Adaptado a cada edad hay que potenciar acciones concretas en favor no tanto de dar como de darse uno mismo.

Las actividades en torno al voluntariado, que es servicio desinteresado a los más necesitados, constituyen un medio adecuadísimo de la educación en la generosidad: monitores para gente pequeña en campamentos infantiles, colonias, campos de trabajo en favor de iniciativas sociales (reconstrucciones de iglesias, construcciones de centros cívicos, etcétera); bancos de alimentos; campañas de promoción rural; dispensarios en zonas pobres; campañas de higiene o alfabetización, etcétera, constituyen ejemplos prácticos donde se desarrolla la virtud de la generosidad y se favorece la causa de la paz.

Muy unida a lo anterior está la educación en la virtud de la sociabilidad. La persona es un ser social, necesita de los demás para su propio proceso de mejora y tiene el deber de ayudar a los demás a desarrollarse lo mejor posible.

La sociabilidad se orienta hacia la solidaridad altruista, basada en los principios supremos de la caridad y del amor al prójimo, superando cualquier planteamiento utilitario.

Ya desde pequeños hay que educar a los hijos para que aprendan a convivir con un grupo de personas — de ahí la conveniencia de que el niño aprenda a estar físicamente en un mismo lugar con sus semejantes- y, por tanto, introducirlos desde niños en grupos ajenos a la familia y participar, sobre 
todo a partir de la adolescencia, en iniciativas sociales de todo tipo (colonias, campamentos, clubes juveniles, excursiones, actividades deportivas, etcétera).

Otra virtud a desarrollar es la virtud del respeto. Ésta se fomenta cuando el niño vive en un ambiente de consideración y de cariño, y cuando contempla el ejemplo de sus padres al tratar al personal de servicio de la casa o, al contrario, al criticar indiscriminadamente a cierto tipo de personas por su raza, origen o profesión. Esto sí que condiciona tremendamente al niño.

Hay que enseñarles a buscar lo positivo en los demás, enseñarles a agradecer los esfuerzos de los demás en su favor, a no criticar a sus semejantes. Todo esto será fácil si lo comprueba hecho vida en sus padres y educadores, en caso contrario se hará muy difícil.

Al llegar a la adolescencia, el respeto tiene mucho más sentido, con una intimidad propia descubierta que permite a los adolescentes reconocer lo que significa respetar a los demás y respetarse a sí mismos.

El respeto está basado en el conocimiento de la condición y de las circunstancias de la otra persona. De ahí se deriva la importancia de dar a conocer, de instruir en el conocimiento de otros pueblos, culturas, etnias, etcétera.

Es aquí donde cobra un sentido educativo, más pleno y no meramente pragmático, el aprendizaje de idiomas que facilita la comunicación, el intercambio y el conocimiento mutuo. Conocer para respetar, podría ser la síntesis de este objetivo.

Finalmente quisiera reivindicar, aunque soy consciente de lo delicado de este tema, la necesidad que hoy tenemos de educar en el recto sentido de la virtud del patriotismo. Lejos de excesos nacionalistas, el patriotismo no es un sentimiento ciegamente apasionado; es un amor generoso y lúcido que es preferencia por el país propio y amor fraternal por las otras naciones. Ama la diversidad y la riqueza de las civilizaciones, de las culturas y de las tradiciones. Ama en cada hombre y en cada familia humana, esa variedad y esa originalidad que es signo 
de personalidad. El patriotismo - que es una virtud- no debe quedar restringido a la preocupación por el propio país. La responsabilidad del ser humano es para con todos sus semejantes.

Hago una llamada a padres y centros educativos para que enseñen a conocer la historia y la cultura de otras naciones, sin falsearla, mostrando lo maravilloso y lo bello que hay en todo hombre, en toda comunidad, en todo el mundo.

\section{¿POR QUÉ EDUCAR PARA LA PAZ?}

Es de justicia reconocer que el movimiento pacifista internacional — cuyas protestas alcanzaron su punto álgido a principios de los 80- ha obtenido notables éxitos: el acuerdo para la eliminación de misiles nucleares de alcance intermedio en 1985 o la disolución del conflicto Este-Oeste, simbolizado en la histórica fecha del 9. XI. 1989. La búsqueda de la paz se ha convertido en una sensibilidad mundial, general de la sociedad.

Ahora bien, hablar de educar para la paz no es hablar de pacifismo, vocablo ambiguo y muchas veces manipulado por intereses ideológicos sectarios. La violencia más estructural se gesta y mantiene en la medida en que cada individuo concreto la tolera y asume como un elemento más de la realidad. De ahí la necesidad de que nuestros alumnos sean educados para la paz.

Nos referimos ya a cuáles eran —desgraciadamente- los valores, o mejor dicho los contravalores, imperantes hoy en nuestra sociedad, por eso se hace imperiosamente necesario y urgente cambiar ese planteamiento que no favorece una visión altruista y de servicio del hombre y, por tanto, una dinámica a favor de una educación para la paz.

¿Por qué educar para la paz? El fundamento último es el respeto al ser humano considerado como igual, sin discriminaciones en cuanto a dignidad y a derechos fundamentales. Esta dignidad hace que no podamos soportar que otra persona, otro grupo social, otras razas, otros pueblos, puedan ser objeto de violencia, de explotación, de opresión. 
Si existe amor y respeto a la dignidad de los demás, base de la paz, y si esta actitud es consistente y constante, ese amor será ingenioso en la tarea fraterna de educar para la paz.

\section{CONCLUSIÓN}

El ideal y el compromiso de luchar por intentar construir un mundo mejor, más justo y solidario, donde la paz entre las naciones y personas sea el denominador común puede verse como un objetivo ya no sólo difícil de conseguir, sino meramente utópico, tal vez sólo un conjunto de buenas intenciones... irrealizables.

La paz, la educación para la paz, ¿una utopía? Pienso que no. ¿Una aventura maravillosa?: Sí.

Pero es que en la vida del hombre, en nuestra vida, debe haber algo de utopía y de aventura. Lo expresaba muy bien un pensador alemán: "Donde no hay nada por lo cual valga la pena morir, no merece la pena vivir"

La función de educar conlleva implícitamente ese algo de utopía y de aventura, casi nunca la gratificación a corto plazo.

"Todo hombre carente de educación es la caricatura de sí mismo", manifestó el filósofo y poeta alemán Schelegel y nosotros, profesores, educadores, padres, podemos contribuir, y mucho, a construir esa nueva sociedad y ese nuevo hombre, tal vez comenzando por nosotros mismos, tal como lo vislumbraba el gran novelista francés Flaubert: "La vida ha de ser una incesante educación" "?

En todo caso, vale la pena comprometerse en algo tan noble y tan justo; contribuir a la causa de la paz bien puede dar sentido a toda una vida. Ya lo decía San Agustín: "La paz constituye un bien tal, que no cabe desear otro más preciado ni poseer otro más útil ${ }^{8}$.

${ }^{6}$ SCHELEGEL, F., Kritische Fragmente, Aathenäum, 1798.

7 FLAUBERT, G. , Pensées, 208.

${ }^{8}$ SAN AGUSTÍN, De civitate Dei. 


\section{BIBLIOGRAFÍA}

ACEPRENSA (Agencia de noticias): Servicios 69/87, 71/87, 103/88, 142/88, 182/88, 8/89, 33/90, 98/91, 157/91. Madrid. GÓMEZ PÉREZ, R.: Introducción a la Ética Social, Ed. Rialp, Madrid, 1989.

HERRÁN, Pedro de la : Tu Vida, Ed. Rialp, Madrid, 1989.

ISAACS, David: La Educación de las Virtudes Humanas, Ed. EUNSA, Pamplona, 1988.

LEDERACH, J. P.: Educar para la Paz, Ed. Fontamara, Barcelona, 1984.

PIRE, Dominique : Construir la Paz, Ed. Fontanella, Barcelona, 1969.

RATZINGER, J.: Una mirada a Europa, Ed. Rialp, Madrid, 1993. REY-HERME, A.: ¿Guerra o Paz? ¿Para qué Educamos?, Ed. Atenas, Madrid, 1967.

Varios: Veinte Claves para la Nueva Era, Ed. Rialp, Madrid, 1992. Varios: El Mensaje Social de la Iglesia, Ed. Palabra, Madrid, 1991. Varios : Juan Pablo II y el Orden Social, Ed. EUNSA, Pamplona, 1981. Varios: Juan Pablo II y los Derechos Humanos, Ed. EUNSA, Pamplona, 1982.

Varios: Educar para la Paz, en revista "Comunidad Educativa" no 193, Ed. ICCE, enero, 1992.

Varios: Educar desde la Paz, en revista "Comunidad Educativa" no 202, Ed. ICCE, enero, 1993.

Varios: Educar en los Valores, en revista "La Escuela en Acción" Ed. Siena, mayo, 1993.

XARES, X. R.: Educación para la Paz, Ed. Popular, Madrid, 1991. 